\title{
Factors Contributing To Employee Decisions To Ignore Diversity Policies
}

Victoria L. Figiel, Troy University, USA

Mary Ann Kummel Sasser, Troy University, USA

\begin{abstract}
Diversity is examined beyond the traditional definitions in the context of employers and the changing workforce. Realization by employers of non-compliance with diversity policies is revealed, as well as an exploration of reasons why perceptions and lingering stereotypes exist. Solutions for training the workforce on successfully embracing differences are explored to provide employers with the tools to commit to their missions and cultural goals for a diverse workplace.
\end{abstract}

Keywords: diversity, stereotypes, conflict

\section{INTRODUCTION}

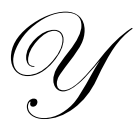

ears of experience in the field of human resources, as well as business management, will expose a manager to situations where employee actions are in conflict with a company's policy relating to maintaining an environment free of harassment. A word spoken, a joke recounted, an inappropriate touch, or worse, these incidents occur at all levels of pay and responsibility. Resolution of these cases involves internal and external resources and can result in costly decisions that affect the company from many angles. Legal issues are ever present, as well as impact to the business relating to distractions and potential loss of knowledge with negative outcomes in the discovery of a terminating offense.

Despite the fact that companies train employees upon hire, conduct ethics tests, online training and targeted anti-harassment trainings, employees still make decisions to break the rules with their behavior when it comes to diversity. With this type of decision, they risk reprimand, at the least termination, or the high potential cost in loss of family and community reputation. Some individual behavior within groups and, ultimately, reflective of the organization itself, continues to run counter to written policy. It would be valuable to organizations and managers to better understand the factors that motivate an employee to make such a high-risk decision. Areas to be explored include the changing definition of diversity in work environments, relationships and perceptions among co-workers, training effectiveness, and employee accountability compared to organization expectations.

\section{LITERATURE REVIEW}

Ashkanasy, Hrtel, and Daus (2002) discuss diversity and emotion as two areas of research in organizational behavior. Understanding employee behavior in regards to diversity forms the crux of this paper. The authors discuss changes in these concepts that will have future implications for companies. Managers today must look beyond the traditional diversity themes of race, gender and sex to further explore the emotional domains of communication styles. Trends toward globalization, a service economy, increased technology and knowledge work play a dominant role in these changes.

Favorable results managers and organizations can realize with this exploration are: increased efficiency in work, which will lead to customer satisfaction; maintaining a competitive edge; ability to better investigate and resolve emotional and diversity issues; heightened awareness/understanding of the preferences, values and emotional expressions of diverse individuals. The more managers understand the fields of diversity and emotional responses, the better they can understand the interaction between the tasks and social aspects of the workplace, as well as employee reactions to those elements. With that understanding, the better equipped they will be to create an 
environment that promotes positive, motivated employees who will act in compliance with company expectations. One very important piece of knowledge gained from Ashkanasy, Hrtel, and Daus (2002) is the trend toward the necessity of hiring employees with strong interpersonal skills. Then, the company must invest in stronger training and communications to be successful both internally and externally with diversity practices. This information provides insight into why companies value the need for diversity. It also provides thought for areas companies must explore for eliminating employee resistance to policies.

\section{EMBRACING DIVERSITY}

In his article, Cadrain (2008) discusses why companies are embracing diversity, as it relates to gay, lesbian, bisexual and transgender (GLBT) employees specifically. Embracing diversity at this depth is not only about the company's image, which can be positive as a result of this strategy, but also about attracting and retaining the best employees, as well as achieving a better level of competitiveness. Most of the Fortune 500 companies are recognizing this younger generation's demand for inclusiveness and are benefiting from the innovation that more diverse teams bring. Cadrain reveals that education is the key for companies to change the behavior of employees toward embracing diversity.

One of the issues explored in this paper is the presence of policy, but Cadrain (2008) explains that training brings this type of policy to life and is the means for allowing a corporate culture to "catch up" with a corporate policy. Specific conflicts are discussed, such as where to draw the line between acceptance of a lifestyle or a religious practice with which an employee does not agree, and tolerance for the different lifestyles and religious practices found in a diverse group of people. Ways to create a diverse environment are to be inclusive in benefit policies, send the message from top management throughout the organization, develop training programs and include expectations for maintaining a diverse work environment in the performance expectations of managers. HR managers are also warned to expect conflict on such volatile subjects and same-sex benefits and to be clear in the communications of the company expectations for diversity. Clearly, managers must seek to understand why employees do not internalize the value of maintaining a respectful and diverse environment, therefore practicing it in their daily behavior and interactions with each other in the workplace.

\section{DIFFERENT GENERATIONS' DIVERSITY EXPECTATIONS}

Gibson, Ivancevich, Donnelly, and Konopaske (2009) discuss the generational emphasis or preferences of employees in the workplace. Of particular interest here are the observations that Gen Xers (born between 1965 and 1976) understand the importance of diversity. The list of workplace preferences of Gen Y members (born between 1977 and 1997) though, do not count diversity in the mix, which leads to the possible conclusion that diversity is something ingrained from parents and not needed as special note. Gen Y expects diversity and a giving culture in the workplace which is also supported by Cadrain (2008). Workplace preferences for Gen Y include: a fair boss, belief in the company, safety in the workplace, work that is meaningful, training and learning opportunities, flexibility in work schedule, constructive feedback, and timely and fair reward systems, but no additional mention of diversity.

\section{PERCEPTIONS THAT CREATE CONFLICT}

Nobel Memorial prizewinning economist, James Heckman, discussed affirmative action and other matters relating to minorities and women (Grossman, 2001). He shed light upon some of the results of organizational actions and societal influences, which relate to this research on behaviors in conflict with policies. His discussions centered on Polish discriminatory practices from the 1920s and the government's attempts to reverse those policies. This research contributed to an understanding of human behavior and provided an understanding that all behavior in conflict with diversity ideas is not intentional, but could be a reflection of societal prejudice. Due to the extreme amount of anti-Semitism in the 20's, the Polish government only allowed the most intelligent Jews to be admitted into medical school. As a result, the population believed that the Jewish doctors were the best. In order to try and reverse this perception, in the 30's, the government allowed only the least intelligent Jews into medical school, and none of the smart were admitted. 
Grossman (2001) makes the comparison to affirmative action policies and the reverse type of stereotype being created for black Americans. He posits that a perception exists that black individuals experience success because they were minorities hired and promoted under affirmative action policies. This perception discounts the competency of these employees and leads to a stereotype and to one of the many conflicts among diverse groups of employees in business. This type of stereotype is only one of many different conflicts that exist, and prevents the internalization of a sincere belief in valuing diversity among groups of employees.

\section{FAILURE TO ACHIEVE TRUE CHANGE FOR A DIVERSE CULTURE}

Hastings (2008) writes about the difficulty that companies are experiencing with a true change in cultures to embrace diversity. Hastings highlights weaknesses in the field pointing to areas of race and gender, in particular. $\mathrm{He}$ also points out self-evaluations revealing a lack of awareness and an inability to show how diversity affects the bottom line. It is becoming more important to Human Resources departments today to be able to show upper management the bottom-line results, in addition to the ethical considerations for doing the right thing when it comes to diversity. The traditional reasons still exist for doing the right thing, and the legal reasons directly influence bottom-line results.

A 2008 report by The US Equal Employment Opportunity Commission reveals high claims of discrimination in the legally protected classes of employees in the American workforce. Despite the growing implementation of diversity programs in companies, the trend to report discrimination has increased and the cost has topped hundreds of millions of dollars.

Lackey (2008) points out lack of leadership and commitment to diversity as reasons why employees fail to embrace diversity. Situations of "cross cultural misperception" are described as those well-meaning companies that deny that the existence of differences in multiculturalism exists in their organization. The diversity programs reflect leaders who are unprepared to deal with true issues and end up teaching employees to be "colorblind" and treat each other as if there are no differences, when instead they should create awareness of the value of differences to the company, and to recognize and respond to differences. Many companies implement diversity training to suppress complaints when they should be encouraging open communications about issues that will allow the company to address cultural and diversity conflicts. This information will provide insight into employee choices that are driven by a lack of leadership in the diversity effort.

Lockwood (2009) focused on views regarding women in management as related to behaviors by men and society that conflict with diversity initiatives. Traditional social attitudes and deeply rooted exclusion of women in business roles have existed until the last couple of decades in many countries. Lockwood also points to India, and highlights the stories of successful professional women in India and their observations. They explain that successful acceptance of women in management and their roles results from the serious pursuit of company initiatives for diversity as well as the continued evolution of HR diversity policies, practices and education. One of the keys is to developing, encouraging and empowering women in management roles is to provide challenging assignments and to allow them the opportunity to participate, and be taken seriously in the more traditionally male-dominated aspects of business. These women are also greatly aided by strong mentors.

\section{MANAGEMENT THEORY}

There are prejudices that exist in human beings and are part of the culture of various societies, including America. Stereotypes exist that elevated men's abilities to achieve more in roles such as sales, marketing and production and were better leaders while women remained in roles in HR, PR and administrative roles at low levels. These perspectives explain behaviors discussed here. Actions recommended include that senior management must have not only a commitment to hire women into management but must also link their advancement to business strategies. Much like the effort in America, behavior experts in India promote the need for a collective effort to change mindsets to overcome gender differences. Recommendations for companies in India to promote the inclusion of women are reflective of other research conducted for this paper: develop policies to include women; develop training programs for women in career guidance, leadership development and mentoring; promote awareness; elicit input from women regarding relevant policies and processes; make accommodations in relocations 
for both spouses; have a true commitment to inclusion of women in business strategy, as well as hiring and promoting practices (Lockwood, 2009).

Conflict with diversity initiatives can take place as a result of group behavior and a key to involvement relates to group inclusion. Authors Nishii and Mayer (2009) discuss this issue. They explain that "in-group" and "out-group" behavior can apply to all types of diversity in an organization. Management should take a critical, deep level of understanding of this type of group behavior for retaining employees.

The Hersey-Blanchard Situational Leadership Model (Hersey, 2009) is explored as a management model which can help managers coach employees to comply with expected behaviors and policies, in this case, embracing a diverse culture, as part of their job requirements. Hersey's focus on the readiness level of associates provides a three step process which helps to ensure the company missions and goals through a format that is directly related to the employee's behaviors and actions are met. Management should find this and other ways to focus on individual behavior for ensuring the workplace embraces diversity concepts and culture.

\section{CORE CONTRIBUTION FOUNDATION}

Despite the fact that companies spend monetary and human resources on creating diverse work environments, they continue to experience the consequences of employee behaviors in conflict with these efforts. Traditionally, companies implemented policies and training programs to be complaint with laws regulating equal opportunities for race, gender, age, disability, religion and national origin differences. As the growth of the diversity movement has taken place, a perception that the more diverse the members of teams are with their backgrounds, functional experience, perspectives and values; the more successful the group will be regarding performance, morale and other factors. However, studies have produced mixed results on the effects of diversity on team performance (Gibson, Ivancevich, Donnelly, \& Konopaske, 2009). The differences in more outward appearance alone, for example gender and race, have not shown improvement in team productivity. It takes a second look to understand the different types of diversity for teams to explain what companies need to consider with the makeup of their teams. In certain cases social diversity, or the differences in perspectives based on race, gender and ethnicity, lead to increased morale in groups. Information diversity, which is based on knowledge base and perspectives that can be contributed, can increase group performance. However, groups who have value diversity, not shared values, do not achieve better performance. Companies need to group people with shared values on the team, and consider the other types of diversity to be a positive factor for the team structure.

When delving into human differences, the focus on the emotional and management styles of individuals has led to the popularity of using various personality tests to match personality types to certain jobs. The Myers-Briggs Type Indicator (MBTI) is considered to be useful for many well-known companies (Gibson, Ivancevich, Donnelly, \& Konopaske, 2009. This test has not been shown as valid and reliable, however, but some companies believe that it is an accurate indication of whether or not a candidate will be a good fit for a position and is a good measure of whether they will perform effectively in a given capacity. There are discrimination concerns for companies when they are dealing with a test that is not reliable and valid, but there are high benefits to hiring people they believe will succeed.

The existence of strong corporate policies, guidelines and practices are a solid first step for companies who want to be diverse, but not enough for achievement of a diverse workplace (Cadrain, 2008). Commitment and training are required to meet the growing demand of tolerance for people's differences. Human Resource professionals are discovering that these policies are not enough. The incidents that are being reported with company hotlines, and complaints that have been suppressed with other approaches, are proof that a problem still exists in the workplaces of today. The US Equal Employment Opportunity Commission reports that from 1997 to 2007, the number of complaints filed under all statutes watched over by this US agency stayed fairly close to the 80,000 range or just below, with a low of 75,428 in 2005 and a high of 84, 442 in 2002. However, there has been a significant increase from year to year in the recent three, starting with 75,768 in 2006 to 82,792 in 2007 to a record in 2008 of 95,402. Many of these complaints may not be valid. An average of $60.1 \%$ have been determined to be without reasonable cause, but the cost of these cases in monetary benefits topped the charts in 2007 at $\$ 290.6$ million, which does not include monetary benefits obtained through litigation (EEOC, 2008). Do the Human Resource 
professionals who are defending the company in these cases discover that upon investigation of these complaints, the lack of respect for individual differences truly do not exist in all areas of their companies? They may realize in a very serious environment, in a disappointing light, that all of their efforts at training were in vain. Discovery in their legal investigations disclose that employees are not following the policies, do not respect the diversity of others, and behave in inappropriate, costly ways that jeopardize themselves and the company, as well as hurting others.

The Society of Human Resources (SHRM) conducted a survey that revealed self-evaluations by Human Resources professionals exposing their frustration with the difficulties of justifying the bottom line results that a truly diverse workforce can achieve, as well as an admission that despite policies, issues and conflict still exists, especially in the areas of race and gender (Hastings, 2008). A recognition that this problem exists is critical in exploring why some practices are not working. In addition, they must recognize the breadth and depth of the diversity topic, educate themselves and their management team on the development of knowledge in this area that has evolved from when diversity was first being discussed in organizations and institutions of learning. A realization of the areas previously explored in this paper can lead to better implementation of policies through better training programs. It will also help Human Resource professionals explore how to solve these problems and achieve the type of environment that their company mission statements claim, and their companies sincerely want to achieve.

Many of the stereotypical views in cultures are deep-seated and enduring. They are part of the history that people have experienced, both shared and as a result of conflict. They are part of traditions that have been perpetuated. Even the offensive humor that is investigated by Human Resource Managers is something that is embedded in the behavior of people and endures through generations. A 2009 article in SHRM (Lockwood, 2009) discusses the difficulties women in India have experienced and still face, due not only to traditional views that women did not belong in business or roles outside the home, but also the enduring expectations that women balance the responsibilities of the family, even with the caretaking of in-laws, in addition to whatever roles outside the home they undertake. This lingering bias also exists in America, although India lags behind a couple of decades in their movement against this stereotypical behavior. Despite advances and positive growth in the percentages of successful women at the top in corporations and government roles, America still shows high numbers of claims on gender and race discrimination with the EEOC, as well as the corporate demand for defense against these lawsuits. Human Resource managers still fight the battles of inappropriate workplace behavior relating to all of these protected classes. Cultural views and prejudice against different religious practices exist in most nations. Grossman (2001) discusses the anti-Semitism of the Polish government in the 30s highlights, the existence of discriminatory behavior, an attempt to reverse it, and the failure to achieve change. This is an example of how difficult it is to affect change with entrenched beliefs, no matter how misguided those beliefs are. There are similarities to the same thought processes that have endured in the racial stereotypes in America, not for Jewish religious beliefs, but for black Americans because of their color and their racial backgrounds. One could even expand on the same stereotyping that assumes white Americans are prejudiced or that southern Americans who speak with a slow accent are not intelligent.

Finally, there are many theories that discuss motivation and the needs that drive people's behavior (Gibson, Ivancevich, Donnelly, \& Konopaske, 2009). Managers cannot expect to understand why employees choose to act in conflict with corporate guidelines without understanding the varying individual needs, motivations and goals that are internal to employees. The rewards and punishment determined for groups and individuals as well as the goals set for them are linked to this knowledge of what motivates them. Finding that motivation is key to the success of training, and management of individuals for performance and compliance with corporate goals, missions and cultural expectations.

\section{CONCLUSION}

Cadrain (2008) mentions the required first step for companies is to develop strong policies relating to antiharassment, clear guidelines and a mission statement that fits the company's desires to maintain a diverse culture. It is important to pair the publication of this policy with a management philosophy that sincerely supports it. Many companies such as Shaw Industries, Inc., create diversity champions and the training begins at the top level of management. Then the training works its way down through the management ranks and becomes a part of smaller teams who work on shared goals that connect employees, share cultures and bring visibility and respect to 
differences, reflecting the true commitment and buy-in of upper management to the practice of diversity. This visibility is an important step to include.

There are many sources to benchmark from companies that publish their diversity statements on their websites, which reveal the awareness and education of the depth of diversity and the recognition that inclusion goes beyond the traditionally known diversity traits of age, race and gender. Cadrain (2008) points out the importance of companies to train employees at a deeper level on the definitions of diversity and to teach a respect for individual differences instead of promoting environments that ignore the very differences that could help with understanding, which could help prevent discriminatory behavior. A trend toward globalization supports efforts to train this knowledge into industries, and provides data that encourages companies to get on board with educating the workforce on varying religious and cultural practices, as well as generational and sexual preference. The results of this training process grows an appreciation of human differences that can result in higher levels of service to customers as well as attracting and retaining and driving to high performance a diverse culture of talented employees (Gibson, Ivancevich, Donnelly \& Konopaske, 2009).

It is critical for companies to develop, implement and enforce a method of leadership practices for their management team, which will allow managers the ability to understand their employees and their needs well. This type of practice will align managers and their associates with the true missions and goals of the company. There are many suggested management practices to consider. One popular method managers work with is the HerseyBlanchard Situational Leadership Model. This model helps managers assess the readiness levels of their associates so that they can lead them to performance through directing, coaching, supporting, or delegating. How does this help a manager with the issue of compliance with diversity and company policies? Managers must examine the strengths and weaknesses of their associates in order to determine what level of coaching to apply for reaching performance goals. A natural result is that the manager is working more closely with the associate and can pick up on issues with the employee's behavior and actions. In following three steps of this model, the manager not only identifies the specific job, task or activity, but also establishes a mutual understanding with the subordinate employee regarding the job requirements, which in this case can include the importance of inclusion and diversity values and their specific application to the job. The next step is to determine the employee's current performance readiness, which includes their ability (knowledge, skills, education) and willingness (confidence, motivation, commitment) to perform. This is a critical time for the manager to determine if the employee is educated in the area of diversity and is willing to be inclusive in their work responsibilities. The final step is to match the manager's style to the readiness level of the employee, which focuses on the relationship behavior to be applied (facilitating, participating or involving) and task behavior (amount of guidance or direction provided) appropriate to the employee needs (Hersey, 2009).

Another recommendation is to use the relationship concepts in the Leader-member Exchange Theory (LMX) to build acceptance of diversity in teams. The basis of this theory is that the leader will have shared values with what is called an "in-group" of employees, who are considered more favored, while the "out-group" of employees have less in common with the manager, and experience less synergy and a lower quality of interaction with the rest of the team. A 2009 article by Nishii and Mayer reveals that when a manager reinforces negative beliefs about women and minorities being of a lower status than non-minorities in the group, the "in-group" shares the same beliefs and behaves in a negative way with the women and minorities. This is a powerful influence not only on the in-group, but also on the out-group and, in time, will result in turnover. If, in application, the managers of groups instead promote positive interactions with women and minorities, such as inclusion and respect for ideas, making sure that all employees embrace them at the same level of status as the non-minority team members, then the "in-group" logically will embrace these same opinions and interact with these employees in a positive way, creating very healthy work environments that embrace diversity and retain employees with differences. This is a way in which the LMX relationship can be used to maintain compliance with policies and create cultures that are in line with the goals of management (Nishii \& Mayer, 2009).

It is noted that companies can make a difference in the way that they manage their cultures. Companies can create climates within their organizations that positively influence associates and their behavior, as it relates to the way that decisions are made, and that is what directly results in actions that employees take. By creating a visible diversity policy and making associates more aware of their commitment to diversity and other ethical 
behaviors, they can achieve the results they are seeking in today's changing workplace (Gibson, Ivancevich, Donnelly \& Konopaske, 2009).

\section{AUTHOR INFORMATION}

Victoria L. Figiel is a professor at Troy University, and has 28 years in management with a large telecommunications company. Dr. Figiel is a certified Project Management Professional and Six Sigma Green Belt. She has numerous publications in national and international journals.

Mary Ann Kummel Sasser is a graduate of Auburn University with a BS in Public Administration who conducted her internship with the State of Alabama EEOC. She has 23 years of sales, marketing and human resource management experience with two Fortune 500 corporations, is a certified Six Sigma Green Belt (Shaw Industries, Inc.) and a Senior Professional in Human Resources (SPHR) with the Human Resources Institute (HRI). She is currently pursuing the MSHRM with Troy University. In addition to her passion for family, Ms. Sasser is an active community leader for Junior Achievement, PTA, and her local church.

\section{REFERENCES}

1. Ashkanasy, N. M., Hrtel, C. E. J. \& Daus, C. S. (2002). Diversity and emotion: The new frontiers in organizational behavior research. Journal of Management, 28(3), 307-338.

2. Cadrain, D. (2008). Sexual equity in the workplace. HR Magazine, 53(9), 44-48,50.

3. Gibson, J. L., Ivancevich, J. M., Donnelly, Jr., J. H. \& Konopaske, R. (2009). Organizations, behavior, structure, processes (13 ed.). New York, NY: McGraw-Hill Irwin.

4. $\quad$ Grossman, R. (2001). Behavior at work. HR Magazine, 46(3).

5. Hastings, R. R. (2008). SHRM 2007 State of workplace diversity management report: A call to action. Society For Human Resource Management, Retrieved 01/15/10 from: http://www.shrm.org/hrdisciplines/Diversity/Articles/Pages/StateofDiversityManagement.aspx

6. Hersey, P. (2009). Situational leaders. Leadership Excellence, 26(2), 12.

7. Lackey, S. (2008). Expert: International diversity programs need backing from the top. Society For Human Resource Management, Retrieved 01/16/10 from: http://www.shrm.org/hrdisciplines/global/Articles/Pages/DiversityProgramsNeedBacking.aspx

8. Lockwood, N. R. (2009). Perspectives of women on management in India. Society For Human Resource Management, Retrieved 01/17/10 from: http://www.shrm.org/Research/Articles/Articles/Documents/090677_India_Women_Ldrshp_FNL.pdf

9. Nishii, L. H. \& Mayer, D. M. (2009). Do inclusive leaders help to reduce turnover in diverse groups? The moderating role of leader-member exchange in the diversity to turnover relationship. Journal of Applied Psychology, 94(6), 1412-1426.

10. The US Equal Employment Opportunity Commission (2008). Report All Statutes FY 1997 - FY 2008, Retrieved 02/04/10 from: http://archive.eeoc.gov/stats/all.html 


\section{NOTES}

